\title{
Context, Content, and Relativism*
}

\author{
Michael Glanzberg \\ University of California, Davis \\ Forthcoming in Philosophical Studies
}

Here is a simple and inviting picture: the semantic values of sentences, relative to contexts, are sets of possible worlds. These are the truth conditions of assertions of those sentences in contexts. They are thus the contents of assertions, or the objects of attitudes we might take towards such contents.

There have been many questions raised about the simple picture. For instance, sets of worlds might well be too coarse-grained to capture fully the objects of attitudes, leading to more fine-grained or structured contents. But opting for structure does not conflict with truth conditions being sets of worlds, and so, I shall ignore this sort of question. I shall likewise ignore questions about the nature of possible worlds.

I propose to ignore these questions to focus on whether the semantic values of sentences should be sets of something more than possible worlds. For instance, it has frequently been proposed that semantic values should be sets of pairs of worlds and times. The simple picture opts for eternalism: semantic values of sentences are eternal truth conditions. This stand in

${ }^{*}$ Versions of this paper were presented at a symposium on relativism at the Pacific APA, 2006, the 'Cog Lunch' at CSLI, 2006, and the Bellingham Summer Philosophy Conference, 2006. Thanks to the participants at those sessions, and especially to Andy Egan and Thony Gillies, my co-symposiasts at the APA, and Brian Weatherson, my commentator at Bellingham. Thanks to Kent Bach, Chris Barker, Cleo Condoravdi, Benj Hellie, Kathrin Koslicki, John MacFarlane, Robert May, and Adam Sennet for helpful comments on earlier drafts. 
contrast to temporalism, which holds that semantic values are time-relative truth conditions.

Temporalism has been subject to a number of criticisms; from Enç (1984, 1986), from Evans (1985), from King (2003), and from Richard (1981, 1982). I shall not be particularly concerned to argue against temporalism here, though I find these criticisms persuasive, and I shall be assuming eternalism. The question on which I shall focus here is whether, on the model of temporalism, we should see any other additions to worlds in the semantic values of sentences. Leaving times to one side, we can distinguish two sorts of positions:

Semantic value absolutism: The semantic values of sentences are sets of worlds.

Semantic value relativism: The semantic values of sentences are sets of tuples of worlds and other parameters, relative to which the truth of a sentence in a context is determined.

The particular form of semantic value relativism I shall discuss most in this paper posits that semantic values of sentence are sets of pairs of worlds and judges. The judge assesses certain claims, like what counts as fun.

As proponents of such views are clearly aware, this is a form of relativism about truth. We can get no truth value from the content of an assertion until we fix the judge relative to whom it is true. But defenders of this sort of semantic value relativism are quick to point out they are not repeating the mistake, all too common among our undergraduates, of just thinking that truth is 'truth for me, and truth for you'. Rather, they argue, there are semantic phenomena we cannot make sense of without making room for relative truth. Furthermore, they will argue, this semantically motivated relativism is more modest, and more sensible, than our undergraduates' version, and so is not vulnerable to a range of standard objections to relativism.

My main concern here shall be with the philosophy of language side of this debate. I shall argue that in fact, thinking about the way language works does not give us any argument 
for relativism. Of course, this comes down to a case by case analysis, and I shall not be able to survey all the linguistic phenomena that people have claimed lead to relativism. Rather, I shall focus on one that I think is among the most cogent and compelling. From examining it, I shall draw some general morals about this sort of argument from relativism. I shall argue that it over-generalizes, and that if we accept it, we will have to be relativists about far more, and far more uncomfortable, things than who judges what is fun. I shall also suggest, in the end, that the argument which leads to this kind of rampant relativism hinges on a particularly stringent view about the way context fixes contextual parameters. I shall suggest this stringent view is not well-justified, and that language shows us many contextual effects which do not conform to it. This will not constitute a knock-down argument against relativism, but I do hope to show that sober reflection on language offers relativism no support. $^{1}$

\section{Some History}

Before discussing my example of semantic value relativism, and the role of judges, I shall sketch some of the history of thinking about the semantic values of sentences. Some important early thinking about contextual factors and semantic values embodied a form of semantic value relativism, but it was fairly quickly rejected. Bearing in mind why it was

\footnotetext{
${ }^{1}$ Semantic value relativism captures one of the important aspects of the current debate over relativism; particularly, the semantic underpinnings of this debate. It is the crucial issue for Lasersohn (2005), which I shall discuss at length below. Though there are some minor differences, it also captures one of the core issues for such discussions as Egan (2007), Egan et al. (2005), and Stanley (2005). MacFarlane (2005) questions whether semantic value relativism is the right way to frame the issue of relativism. Some of his worries, I believe, amount to points about the background assumptions that go into a reasonable and non-trivial semantic value relativism. For instance, for semantic value relativism to be non-trivial, it must be possible for the other parameters in the semantic value of a sentence to vary independently of possible world (and time) and each-other. Furthermore, as MacFarlane reminds us, these other parameters must not automatically be set by context. Relativizing semantic values to a judge parameter meets these conditions. Discussion of other aspects of MacFarlane's favored way of framing the issue, especially his four-fold distinction between 'usesensitivity', 'use-indexicality', 'assessment-sensitivity', and 'assessment-indexicality', I shall have to leave to another occasion.
} 
originally rejected will be helpful in assessing current arguments.

There was a time when practically everyone thinking about (intensional) semantics was a semantic value relativist. If we look at Lewis (1970) or Montague (1968), we see the semantic values of sentences as sets of indices. An index is a sequence of coordinates, each of which is a specific piece of information which can play a role in determining the truth value of a sentence. Indices include values for all of what we now think of as contextual parameters. For instance, Lewis considers:

〈world, time, place, speaker, audience, indicated objects, previous discourse, ...〉

Actually, Lewis goes on to consider even longer indices than these.

The motivation for such indices was to generalize the techniques of intensional semantics to sentences containing context-dependent expressions. Without any context dependence, a possible world (or a world and time) is enough to fix an extension, i.e. a truth value. But once we have indexicals, for instance, we need more information. We need to know who is speaking to determine the truth value for:

(1) I am in California.

The index theory simply proposed to add such information over and above possible worlds, resulting in indices with additional coordinates beyond the world coordinate.

This is a form of relativism: (1) has a semantic value which comes out true relative to me (at indices containing me as speaker), but not to you (at indices containing you as speaker). It is true for me, but not for you.

Any number of objections have been raised to this idea. We could object, with Evans (1985), that we cannot make sense of a speaker asserting anything like the semantic values this kind of theory provides. We could also simply report that it seems slightly silly to have what we say be true for me (as speaker), for you (as hearer), for the cat (as demonstrated 
object), and so on.

Historically, there were two other arguments against the index theory which really carried the day, both of which relate to how context and semantic value interact. Perhaps the main objection to this kind of theory comes from Kaplan (1989b). Kaplan observes that the index theory renders sentences like $I$ am here now basically contingent: there are indices at which it is true, and indices at which it is false. This, Kaplan suggests, gets the logic of indexicals fundamentally wrong. It does so, he argues, because it fails to mark clearly the difference between context and circumstance of evaluation. Once these are distinguished, we can clearly see how I am here now come out both logically valid-understood as being true in all contexts - but also such that I might not have been where I am-understood as failing to be true at some circumstances.

So, Kaplan argues we need to have separate notions of context and circumstance. Once we have them separated, we can see that circumstances of evaluation do not need the extra coordinates. They are just possible worlds (or worlds and times). Hence, the semantic values of sentences in contexts are not further relativized, and we have what I labeled semantic value absolutism.

The other sort of argument, due to Cresswell (1973), targets the account of context implicit in the index theory. The index theory identifies a context with a list of coordinates, each of which is a specific feature of the context that sets a contextual parameter. Cresswell argues that in their role as contexts, we will never settle on indices that are long enough. Lewis already considered very long indices, but Cresswell notes that the considerations which lead to them also lead us to include coordinates for country, climate, religion, and previous drinks, to account for:

(2) a. They're playing the national anthem.

b. What a cold winter we had.

c. The gods are angry. 
d. Just fetch your Jim another pint.

Each of these shows a form of context sensitivity which leads us to add yet more coordinates to our indices. The specific details of some of these sentences might be challenged. (We will soon see reasons we do not need a separate climate parameter, for instance.) But the point that the effects of context are more extensive than the index theory anticipated seems sound.

Cresswell's objection was originally targeted at indices used as representations of contexts. (Cresswell was already assuming a double indexing system, which uses separate indices for the roles of context and circumstance of evaluation.) Aimed at the original index theory, his objection is even stronger. Such a theory would not just make things 'true for you and true for me', but 'true for you, me, and previous drinks'. But there is more to Cresswell's point than that. He notes that we cannot, it seems, specify any settled list of coordinates in an index. The range of coordinates that can go into specifying a context seems to be open-ended, or at least, larger than we can effectively specify. Indices are supposed to build semantic values. The functions from contexts to these should be assigned by the linguistic system - they are part of linguistic competence. But then, we could not make sense of understanding the semantic properties of a language which are part of linguistic competence in advance of understanding the open-ended features which might go into a context.

The open-ended nature of indices to which Cresswell calls our attention might be of two different sorts. On the one hand, the length of an index might have an upper bound derived from the nature of human languages. There might be, in human languages, a fixed range of potentially context-dependent constructions which are available. If so, then indices would be open-ended in the sense that we might not be able to write down what the coordinates of an index really are (absent a full semantics for natural language). On this possibility, the force of the Cresswell objection is that the semantic value of even the most simple sentence would build in something like the complexity of a whole human language. This would make linguistic competence and language acquisition odd indeed. On the other hand, it might be 
that the range of potential context dependence is not so limited. Like the open classes of nouns and verbs, the needed coordinates might be limited only by our creativity, and the complexity of the world we are describing. Presumably, this would make them genuinely open-ended. The Cresswell objection would be all the more serious on this possibility, as it would be hard to make sense of the semantic value of a sentence at all, or in what competence with a sentence could consist.

Cresswell and Kaplan conclude that the index theory fundamentally misses the role of context. Cresswell is here arguing, as Lewis (1980) does, that context determines a wide range of parameters which can go into fixing the contents of particular sentences, but that we cannot identify the context with those determinants. Context determines a range of contextual parameter values, but it is not to be identified with those values.

The picture that emerges from the early discussion of the index theory is that the index theory embodied a confusion about the role and nature of context. It worked context into semantic value, and it tried to identify context/content with a limited list of specific values. The contrasting picture, which became the accepted one, is to reject both. Context and content are distinct, and so a context is a determiner of content, but not part of content. Context is also the determiner of contextual parameter values: it sets certain parameters, but is not to be identified with the parameters that are set.

In the following, I shall show that arguments for relativism lead us back to the bad old days of the index theory. To see this, we need to look at such an argument in detail.

\section{Predicates of Personal Taste}

There have been a number of arguments in recent years that we should abandon semantic value absolutism, and adopt some form of semantic value relativism. One of the best I know 
of is given by Lasersohn (2005). ${ }^{2}$ Lasersohn is concerned with the semantics of what he calls predicates of personal taste, which are formed from adjectives like fun and tasty. These, he argues, require relativization of truth to a judge, who judges things to be fun or tasty. These predicates are treated as functions from triples of world, time, and judge to sets of individuals. We need not worry about the time parameter for the moment, so we can think of them as the sets of things which are tasty or fun in a world, for an individual, the judge. A sentence like chili is tasty is then interpreted as the set of world and judge pairs such that chili is tasty in that world for that judge.

Why introduce the judge, relative to whom we assess truth? In some cases, it is entirely natural. When Mary says Chili is tasty, she seems to report that she finds chili tasty, so that it is tasty relative to her as a judge. If John then announces that chili is not tasty, he may well simply be reporting that he does not find it tasty, and so it is not tasty relative to him as a judge.

As Lasersohn makes clear, this is not yet a case for relativism. It seems the natural way to accommodate this is to see predicates like tasty and fun as having a contextual parameter, which can be set to be John or Mary, in the right context. To make a simple proposal:

(3) $\llbracket$ tasty $\rrbracket^{c}=$ tasty-for- $i_{c}$ (Lasersohn's option 1.)

Here, $i_{c}$ is a parameter which is set by context to be the speaker of the context $c .^{3}$

Lasersohn argues this is not a viable theory. Consider an exchange like:

(4) John: The chili is tasty.

Mary: No, the chili is not tasty.

\footnotetext{
${ }^{2}$ Other recent cases for semantic value relativism include Egan (2007), Egan et al. (2005), Kölbel (2002), and MacFarlane (2003, 2005).

${ }^{3} \mathrm{~A}$ note on notation. I use italics to indicate word or phrases mentioned. $\llbracket \alpha \rrbracket^{c}$ is the semantic value of $\alpha$ in context $c$. I indicate particular semantic values by boldface, so tasty-for- $i_{c}$ is the particular meaning of tasty in context $c$. For our purposes here, we may think of this as a property. In a more formal development of intensional semantics, it would be treated as an intension.
} 
Our current theory predicts this is not a case of disagreement. John expresses the proposition that chili is tasty for him, while Mary expresses the proposition that it is not tasty for her. But we can easily imagine contexts in which we would readily judge that they are disagreeing.

The relativist theory proposes an explanation of how John and Mary disagree. They express sets of pairs of worlds and judges which are disjoint, and so they express that they see things in opposite ways. We should ask if this is really the right account of disagreement, but we may grant to Lasersohn that the simple contextual theory has no account of disagreement, while he does.

The obvious problem with the contextualist proposal as we set it up is that it is too strict. It insists that it is always the speaker of a context who fixes what is fun or tasty. But in sequences of utterances, we can have fixed standards for what is fun or tasty, with multiple speakers.

Can we make a simple modification to the contextualist theory, which will do better? I think we can, but first, let me review Lasersohn's arguments that we cannot. He considers the proposal that we replace the speaker with a relevant individual or group of individuals (his option 2). He then asks us to consider John and Mary on a roller coaster:

(5) Mary: This is not fun.

John: Oh, yes it is!

As Lasersohn argues, if there is a contextual parameter making reference to a relevant group containing John and Mary, and fun is fun for every member of that group, John's response amounts to insisting that roller coasters are fun for Mary, in spite of her claim to the contrary. On the other hand, if we only require that fun be fun for most of the members of the group, then John and Mary's disagreement comes down to what the majority view in the group is. As Lasersohn sees it, neither of these captures the contents that we intuitively think John and Mary have expressed. So, neither correctly accounts for disagreements of this sort. 
The general conclusion, according to Lasersohn, is that we cannot get context to do any job of setting a parameter in predicates of personal taste which correctly captures their meanings. Instead, we need to add a judge to the semantic values of sentences.

\section{Gradable Adjectives}

I think that a better contextualist proposal can be found. There are two problems with Lasersohn's argument to the contrary. One is that he is being a little to quick with what kinds of contextual parameters might be involved in predicates of personal taste. But more importantly, I think he is tacitly making an assumption about what sets those parameters which we should reject.

I shall sketch a sample proposal of how a contextualist might treat predicates of personal taste. It will be a sample only, not a fully detailed analysis. But it will be enough to help us see what is required to avoid relativism.

As a preliminary step, I shall begin by discussing adjectives like tall. Both tasty and fun fall into the same class as tall: the class of gradable adjectives. These are primarily distinguished by taking degree modifiers like very and somewhat:

(6) a. Chili is very tasty.

b. Roller coasters are somewhat fun.

Gradable adjectives like tall are well-studied, and I shall try to adapt what is known about them to the admittedly trickier case of predicates of personal taste.

I shall take an 'off the shelf' analysis of gradable adjectives, due to Kennedy $(1997,2007)$. The main idea is that adjectives like tall locate objects on a scale of tallness. The starting point is the comparative form. For adjectives like tall, the comparative form appears sharp:

(7) a. John is taller than Mary. 
b. The degree to which John is tall is greater than the degree to which Mary is tall.

Kennedy takes the basic meaning of a gradable adjective to be a function from individuals to degrees. In particular, we have a function from individuals to degrees, ordered by some total ordering, with a dimension: a property according to which the degrees are ordered (such as height, length, cost, etc). The triple of degrees, ordering, and dimension is what Kennedy calls a scale. The basic interpretation of a gradable adjective is a function from individuals to degrees of a scale. The comparative form can then be interpreted very simply:

a. John is taller than Mary.

b. The degree to which John is tall is greater than the degree to which Mary is tall.

\section{c. $\operatorname{tall}($ John $)>\operatorname{tall}($ Mary $)$}

Here semantic values like tall are functions from individuals to degrees. ${ }^{4}$

Simple predicates like tall are built out of the positive forms of adjectives. ${ }^{5}$ According to Kennedy's analysis, the positive form says that the degree to which something is tall is greater than some contextually determined value:
a. John is tall.
b. $\operatorname{tall}($ John $)>d$
c. $\operatorname{tall}($ John $)>s($ tall $)$

In simplest form, we look for a particular degree value $d$ determined by context. To be tall in a context is to be taller than that degree $d$. Kennedy in fact argues we need to have the degree value determined by context from the meaning of the adjective (the function from individuals to an appropriate scale), hence, he prefers the more complicated $s($ tall) we see in

\footnotetext{
${ }^{4}$ Degree analyses are also developed by Barker (2002), Bartsch and Vennemann (1973), Cresswell (1977), Heim (1985), and von Stechow (1984). The main alternative, the partial predicate analysis, has been developed by Fine (1975), Kamp (1975), Klein (1980), McConnell-Ginet (1973), and Pinkal (1995). For a recent discussion of gradable adjectives in the philosophy literature, see Stanley (2005).

${ }^{5}$ There are some technical details of how the positive form is derived from the sort of meaning we have posited for the adjective itself, but they will not be relevant here (see Kennedy, 1997, 2007).
} 
(9c). Here, $s$ is a contextually determined function which picks out a contextually significant degree, based on the interpretation of a given gradable adjective. For instance, the function $s$ returns a contextually significant degree of tallness for input tall. The degree $d$ is the value of $s$ in context $c$. I shall refer to this degree value, determined by $s$ for a given adjective and context, as the standard for that adjective and context. According to Kennedy's theory, the standard $d$ for context $c$ is thus determined by the contextually given function $s$ plus the meaning of the adjective. ${ }^{6}$

The account of the positive form given in (9) captures the idea that what proposition is expressed by a sentence like (9a) is context-dependent, depending on what standard of tallness is given by the context. As usual, it might express a true proposition, if the standard is set to a value appropriate for talking about the tallness of jockeys, but a false one if the standard is set to a value appropriate for talking about the tallness of basketball players. There is more to say about the context dependence of adjectives like tall, to which we will return in a moment. But this will be enough to start looking again at adjectives of personal taste.

\section{A Contextualist Proposal}

That predicates like tasty and fun are context-dependent is not all that controversial (pace Cappelen and Lepore, 2005). At least, these expressions show some of the same context dependence that other predicates built from the positive forms of gradable adjectives do: context helps to somehow set the standard for how tasty or fun something has to be to count. Just as someone can count as tall relative to one context, where jockeys are under discussion, and not tall in another context, where basketball players are under discussion; so too a cheeseburger might count as tasty, relative to a context where bad bar food is under

\footnotetext{
${ }^{6}$ Related ideas about functions determining a standard are developed by Barker (2002) and Lewis (1970).
} 
discussion, and not tasty, relative to a context where the best foods in California are under discussion.

The fact that tasty and fun are gradable, and so is tasty and is fun are sensitive to context for what degree is required to satisfy them, indicates an analysis along the lines of the degree analysis of other gradable adjectives. So, we might propose that for each such adjective, we have a scale of values of how tasty or fun something is. We can then interpret their positive forms on the model of (9):
a. Chili is tasty.
b. $\operatorname{tasty}($ chili $)>s($ tasty $)$

This tells us that the degree value of tastiness assigned to chili is greater than the contextually determined degree above which something counts as tasty. ${ }^{7}$

There are a number of things left out of this analysis. First, tasty, like a number of gradable adjectives, can in fact be associated with multiple scales. Tastiness can be thought of as assigning scale values along many different scales: refined delicate taste, brute, forward taste (why are Burgundies and California Zinfandels both tasty?), etc.

Actually, this is not a feature specific to adjectives of personal taste. Many gradable adjectives can be associated with multiple scales. For instance, someone can be smart as in 'book smart' or 'street smart', a large city can be large in population, geography, etc. Fixing the interpretation of a gradable adjective often requires fixing both a scale and a standard value. I shall leave open just how to account for this. It may be that some adjectives, like tasty and large, but not tall, have a contextual parameter fixing the scale. Or, it may be that this is a kind of polysemy. In what follows, I shall often just assume that we have somehow fixed the relevant scale.

Does fixing a scale and a standard fix the interpretation of tasty or fun? It seems it must

\footnotetext{
${ }^{7}$ Though it is a somewhat technical point, it is worth noting that the source of context dependence for the standard is not the adjective itself, but some other component of the positive form.
} 
not, as it still leaves out the personal aspects of personal taste. Being fun or being tasty is still being fun or tasty for someone, and we seem to have left that out.

Actually, it is not obvious that we really have left it out. It might just be that the scale associates the right sort of funness or tastiness with an expression, and that it is a feature of metaphysics or epistemology which brings the experiencers of funness or tastiness into the picture. Maybe it is a matter of how we figure out what is fun, or what it takes for something to be fun, but not anything the semantics sees?

I think there is a case to be made that the semantics does see the experiencers. The primary case is that adjectives of personal taste take complements of the form for/to NP:
a. i. Sushi is tasty to me
ii. Sushi is tasty to everyone on the west coast.
b. i. Roller coasters are fun for me.
ii. Roller coasters are fun for the whole family.
c. * John is tall for/to me.

It appears that we are fixing, with a to or for-phrase, a parameter which otherwise context sets. We also see some evidence from the possibility of binding into the experiencer position, as in:

(12) Everyone had a fun vacation.

This has a reading which requires experiencer classes for fun to vary with values of everyone. As has been discussed at length by Stanley (2000), this gives us evidence of the presence of a parameter the semantics sees. ${ }^{8}$

This is by no means conclusive. We need to know that to me interacts with the semantics of the predicate. For instance, we need to be sure it does not work the way we see in:

\footnotetext{
${ }^{8}$ Thanks to Sarah Moss for the example. There are some significant complications with this case. For instance, the reading is one where experiencer classes vary with values of everyone, but are not identical to them. Some of the apparatus to account for these complications is discussed by Stanley (2000).
} 
But even so, I think we may take it as a working assumption that there is some kind of experiencer parameter in predicates of personal taste. ${ }^{9}$ This parameter is to be set by

\footnotetext{
${ }^{9}$ This is merely a working hypothesis. The main conclusions I argue for here can be made to go through without it. For instance, we could fall back on the idea that adjectives of personal taste are highly polysemous, being associated with multiple scales which differ in experiencer class, but not having an experiencer class parameter. (Depending on one's views about how context dependence works, a range of other options might be available.) The evidence I have presented hints that there is some parameter that the semantics sees, which favors my working hypothesis. Moreover, as a general principle, I am disinclined simply to declare polysemy wherever we see contextual variation. Thus, I think the working hypothesis is the right one.

If there is such a parameter in predicates of personal taste, it raises the question of just what the underlying syntax looks like. The strongest position, and the one I would find most congenial, is that the experiencer class is a genuine syntactic argument of the predicate. The main distinction here is between syntactic arguments and adjuncts. The notion of an argument is roughly that of the argument of a predicate as we see in logic, thought of syntactically. The notion of an adjunct, in contrast, is that of a phrase which further modifies or describes. Thus, John and Mary are arguments, while on the beach is an adjunct, in:
}

(i) John kissed Mary on the beach.

Arguments are inputs to predicates, so if the experiencer class is an argument, it gives us a much more straightforward story to tell about the compositional semantics of predicates of personal taste. This does not mean no plausible semantics is available otherwise, but it is a more formidable task to construct one.

Unfortunately, there do not seem to be any agreed upon tests for syntactic argument status. One test which does indicate that the experiencer class is an argument is the iteration test: adjuncts tend to be iterable, while arguments are not (Larson, 1988). Hence, we see:

(ii) a. * John kissed Mary Sally.

b. John kissed Mary on the beach, under the stars.

We do not see iterability for the experiencer class:

(iii) * Sushi is tasty to me to Mary to everyone.

Unfortunately, there is no consensus that this test alone is conclusive.

Linguists typically note that adjuncts and arguments behave differently with respect to 'extraction' (the moving of expressions out of certain environments). For instance, we have (cf. Fults, 2005; Huang, 1982; Lasnik and Saito, 1984; Williams, 1995):

(iv) a. ? Who do you wonder whether John kissed?

b. * Where do you wonder whether John kissed Mary?

Applying this to the experiencer argument, we get at best mixed results:

(v) a. ?? Who do you wonder whether sushi is tasty to.

b. ?? Who/for who did Mary wonder whether the ride was fun (for)?

My very preliminary inquiries suggest that judgments here are weak. Some informants find cases like these outright unacceptable (indicating adjunct rather than argument status), while some find them marginal. The test is difficult to apply in practice, as it calls for differential judgments between argument and adjunct extractions, but predicts that both should be at least somewhat degraded. And of course, there may be any number of factors involved beyond argument/adjunct asymmetry in these cases. 
context, if not by an explicit statement. The value of the parameter will often be a class, as we see in tasty to everyone on the west coast, though it can be a single individual. ${ }^{10}$

To say there is some such parameter for an experiencer is not to determine how it affects the interpretation of expressions like fun. Presumably, if the experiencer class is not inert, we should see some sort of response dependence in the meaning of fun - where the experiencer class fixes whose responses count. But, how the experiencer class does this, and how much response dependence we see, remain questions. ${ }^{11}$

There are lots of properties which have a significant degree of response dependence, but are not fully so. One example, discussed at length by Wright (1992), is that of being funny. To a great extend, what is funny is what we think seems funny. But not fully. At some point, we are willing to say 'I (or we all) thought that was funny, but you know, it was not'.

I suspect that fun and tasty are more fully response-dependent than funny. At least, we have a harder time with $(14 b)$ in:

a. I thought that joke was funny, but you know, it was not funny.

b. ?? I thought that sushi was tasty, but you know, it was not.

For this discussion, I shall leave these delicate issues about the syntax-semantic mapping unresolved. I shall proceed with my working hypothesis that there is an experiencer parameter in predicates of personal taste. But clearly, the considerations I have mentioned here show the issue needs more investigation. (Thanks to Adam Sennet for lots of information about arguments and adjuncts.)

${ }^{10}$ Example (13) was found by Google: http://www.movie-gazette.com/cinereviews/368. The Google search does bring up some cases like:

(i) Tall to me might not be the same as tall to you, so you imagine what tall is.

(From http://www.austinchronicle.com/issues/dispatch/2006-05-12/arts_feature2.html.) Here, we have what seem pretty clearly to be comparison classes expressed by to me and to you. It is thus not displaying experiencer arguments, but comparison classes. The status of comparison classes will be discussed below. Google also shows lots of instances of the form seems tall to me where to me is the experiencer argument of the verb seem.

${ }^{11}$ Generally, the experiencer class will contain the speaker of a given context. However, this appears to be at best a highly defeasible generalization. There are contexts where the experiencer class does not include the speaker, such as a context where you are talking to a child and saying of some food you yourself cannot stand, but you know the child likes:

(i) Have some tasty hot dog.

The experiencer class for tasty here includes the child, and presumably children like her, but it does not include you. 
I'm not sure we cannot ever say something like (14b), but it is much harder to see where it would make sense.

So, it seems we need to work the experiencer into the meaning of fun and tasty, to a significant degree. I thus agree with Lasersohn that these are really about personal taste, in some way. There are a number of possible ways to reflect this in the semantics. Here is one which makes a minimal departure from the degree-based analysis of gradable adjectives we have been considering.

To take response dependence into account, we will need to see the scales associated with tasty and fun to be experiencer-involving scales. Fun will associate with enjoyment scales, where enjoyment is always enjoyment by some people. Tasty will associate with scales of something like gustatory quality, which again, is quality for some people eating. Note, tasty is not the same as fun, so you can feel 'gustatory quality' without actually having enjoyment. (Think of a painful professional meal at a good restaurant.)

How does the experiencer class determine the scale for an adjective? This brings us back to the question of what fixes the scale. A moment ago I said I would not try to resolve this question in general. I mentioned some cases where it appears variation in scale is a form of polysemy. The case of long looks this way (cf. Kennedy, 1997). Long can mean long in length, or long in temporal duration. But tasty and fun are not obviously ambiguous in the way long is. As a preliminary suggestion, lets us assume that like tall, tasty and fun are associated with single scale type: enjoyment or gustatory quality. But these are parametrized, by the experiencer class argument we identified a moment ago. Hence, the scale for tasty will be gustatory quality as experienced by $E$, where $E$ is some group of people or agents. The scale for fun will be enjoyment as experienced by E. I am not stipulating that enjoyment as experienced by $E$ is uniformly determined by any norm on $E$. I am not, for instance, insisting that it be enjoyment by the average member of $E$. It might be in some cases, but not others. It thus appears to be up to context to work out the right scale 
of enjoyment or of gustatory quality, given $E$. $E$ will typically be set by context, but may also be realized explicitly by a for or to-phrase, or bound, as we have already seen. To fix notation, we have:

$$
\begin{aligned}
& \text { a. } \llbracket \operatorname{tasty} \rrbracket^{c}=\text { degree-gustatory-quality-experienced-by- } E=\lambda x \cdot \operatorname{tasty}_{E}(x) \\
& \text { b. } \llbracket \text { fun } \rrbracket^{c}=\text { degree-enjoyment-experienced-by- } E=\lambda x \cdot \operatorname{fun}_{E}(x)
\end{aligned}
$$

This will give us a working hypothesis about the interpretations of adjectives of personal taste. From it, we can build up interpretations of predicates, including those involving positive forms, in whatever way this is done for other gradable adjectives.

Using this hypothesis, we can identify two or three distinct roles for context in fixing the interpretation of tasty or fun (when no other linguistic machinery appropriates the role):
a. Fixing the standard $s$ (for the positive form).
b. Fixing the experiencer class $E$.
c. Fixing the scale based on $E(?)$.

As I've stressed, the suggestion here is preliminary, and there are many issues about the behavior of adjectives like tasty that I have not investigated. (For instance, Bierwisch (1989) identifies a number of ways evaluative adjectives, including our adjectives of personal taste, differ from other gradable adjectives.) In particular, as I have not presented a general account of how scales for gradable adjectives are fixed, my preliminary suggestion that for adjectives of personal taste it is done by context, based on an experiencer class, is still preliminary at best. But even so, it will give us enough detail to see how we might respond to Lasersohn's challenge.

There were two sorts of objections Lasersohn raised: simple disagreement cases like (4), and more complicated disagreement cases like (5). Lets consider them in turn. ${ }^{12}$

\footnotetext{
${ }^{12}$ Discussion with Brian Weatherson made clear to me that there will be some cases where the value of $E$ is fixed at least in part by something other than context. Consider:
} 
Can we have disagreement between people on claims personal taste? Easily. Our current proposal accounts for cases like (4) as follows:

a. John: Chili is tasty.

$$
\operatorname{tasty}_{E}(\operatorname{chili})>s\left(\operatorname{tasty}_{E}\right)
$$

b. Mary: No, chili is not tasty.

$$
\operatorname{tasty}_{E}(\text { chili }) \ngtr s\left(\text { tasty }_{E}\right)
$$

So long as the context remains constant enough to fix that $s, E$, and the way the scale is built from $E$ remain the same, this is disagreement.

That is all the disagreement we should ask for. In many conversations, we should expect this much stability of context. But whether we have such stability will depend on the context. Consider a number of cases in which dialogs like (4) might occur:

\section{a. i. Normal dialog between Mary and John.}

(i) Joe says sushi is tasty, and it is.

Here, in the first clause, tasty means tasty for a class $E$ which is constrained to include Joe (the referent of the subject). This does not appear to be an effect of context update, as the elided tasty in the second clause need not have this experiencer class at all. It can be for a distinct group, not containing Joe, but containing the speaker.

We see this sort of effect in a range of environments, including says and thinks, and also considers (as discussed by Lasersohn, forthcoming). One common feature of all these environments seems to be that the higher verb (says, thinks, considers) has an experiencer argument (or at least, an agent argument that can be interpreted as an experiencer). Somehow, the experiencer argument of the embedded predicate of personal taste is linked to the experiencer argument of the higher verb. Just what this linking relation is needs further exploration. Semantically, it is simply a relation of membership or identity between argument values (plus whatever we rely upon to account for the de se properties of experiencer arguments). It is tempting to assimilate this to the relation of control, and in cases like (i), to the relation of partial control discussed by Landau (2000). However, this raises a number of difficult syntactic issues. As noted by Lasersohn (forthcoming), the non-subject position of the experiencer argument of the personal taste predicate makes the appeal to control as understood by syntacticians problematic.

The range of cases where we see this phenomenon does not appear to be restricted to predicates of personal taste per se. We also have:

(ii) Joe says roses appear nice, and they do.

Appear also takes an experiencer argument. It seems that the important pattern here is the linking of the experiencer argument of the embedded predicate with an argument of the higher verb. Clearly, more investigation of this is required. 
ii. Disagreement: Presumably there is no drastic context shift between utterances, and so the relevant contextual parameters stay the same.

b. i. Mary and John in separate rooms, musing about food.

ii. No clear judgment about disagreement without more information: John and Mary are in effect in separate contexts. This does not preclude their disagreeing. They might be disagreeing, if e.g. they are talking about their peer group, and the same contextual values are fixed independently by both contexts. But being in separate contexts allows the option of their not disagreeing as well. They might not disagree, for instance, if each is just talking about their own private tastes, with very different values for the relevant parameters fixed by each context. Here, it is what values $E$ takes in the contexts that makes the crucial difference (though $s$ might differ as well).

c. i. Mary and John sequentially tasting different foods. They taste modestly good chili, then John makes his utterance, then they taste the worlds best sushi, and Mary makes her utterance (cf. a 'forced march Sorites').

ii. No disagreement: They share a context in each, but standards of what they count as tasty shift drastically from utterance to utterance. The important contextual parameter in this case is $s$, which shifts as their shared context shifts. Both $E$ and the scale appear to stay fixed.

What about the case of (5)? The problem, as Lasersohn saw it, was we would have fixed that the group contains Mary, who does not find roller coasters fun, and so anything along the lines of 'fun for all the members of the group' or 'fun for the average member of the group' will not get the right results.

By our current analysis, we have plenty of ways to make sense of the disagreement. One is to see them as disagreeing about what amount of fun is assigned to roller coasters. We 
can leave the scale fixed, to be fun for the members of some group including John and Mary, leave the contextually given standard fixed, and have them still disagreeing on whether, for that scale for that group and for that standard, roller coasters have sufficient fun to count as fun in the context. The group that goes into fixing the scale might simply be the two of them, or it might be some group determined by a contextually salient property, such as being the kind of person they are (people who go to carnivals? people who seek thrills?). We do not have to insist that it is fun for all member of the group, or the average member of the group. (For many evaluative adjectives, it is not so clear if we have well-defined averages. We tend, as Bierwisch (1989) notes, not to have meaningful measure phrases to use with them.) Rather, we assume that the right scale of enjoyment based on the group has been fixed, but leave how it has been fixed up to context. ${ }^{13}$

Lasersohn, and a number of other contemporary relativists, point out that their notion of relative truth offers a notion of 'faultless disagreement', where two utterances express disagreement, even though neither is incorrect (cf. Kölbel, 2002). From a traditional, nonrelativist, point of view, this idea is prima facie absurd: if two propositions express disagreement, one must fail to be correct. Of course, this absurdity flows from theoretical commitments of the traditional view, and any such theory must give way in the face of compelling evidence against it. Hence relativists in the spirit of Kölbel and Lasersohn argue that there are linguistic phenomena which cannot be accounted for without the kind of relativist analysis which supports faultless disagreement. At least for the phenomena surrounding

\footnotetext{
${ }^{13}$ There are a great many options for fixing a scale for an adjective like fun, once the experiencer class is fixed. Among the more obvious are those which amalgamate the subjective experiences of enjoyment for people in the group, e.g. taking the minimum enjoyment value across the group (fun means fun for everyone), or the maximum value (fun means fun for someone), or an average (fun means average fun for the group). Often, predicates of personal taste get a kind of generic reading (fun means fun for the typical or generic member of the group). In some cases, we should look to psychology to tell us what is involved in certain sorts of experiences. In the case of taste, for instance, this is likely to tell us a great deal about how scales might be derived from classes of experiencers. Interestingly, in some cases, informants tell me that the size of the experiencer class matters to which scales are appropriate. At least, for a two-person experiencer class, there might be a default preference for the minimum value reading. (Thanks to Cleo Condoravdi for pointing this possibility out to me.)
} 
predicates of personal taste, I have argued here that this is not so. I have argued that the cases of disagreement Lasersohn presents can be handled perfectly well by my contextualist analysis, and so do not present any evidence for relativism. They thus present no evidence for faultless disagreement either. My own inclination is to side with the traditional view, and reject the notion of faultless disagreement as absurd. ${ }^{14} \mathrm{I}$ have not argued for this conclusion directly, but I have argued that sober reflection on the semantics of predicates of personal taste gives us no reason to accept any notion like faultless disagreement.

I conclude that the argument for relativism from Lasersohn's cases does not go through. But let me note some features of the analysis I have proposed here that we have relied upon to make it evade his objections:

i. We need a contextual value for $s$ to be set, where $s$ is a contextual parameter distinct from the experiencer class and scale.

ii. We need the experiencer class $E$ to be set, where its value can be more general than the specific person speaking, or the specific people involved in a discourse.

iii. We need the scale to be set in terms of an experiencer class.

iv. We may need the relation between the experiencer class and the scale to vary with context. (This was our working hypothesis, and we relied upon it in responding to the argument from Lasersohn in 5.)

\section{Metasemantics}

So far, I have argued that we can tell a more or less plausible semantic story about predicates of personal taste, which does not lead to relativism. But in doing so, we have asked context

\footnotetext{
${ }^{14}$ This is indeed, as the relativists remind us, a theoretical commitment; but the theory it flows from is, to say the least, a very very good theory.
} 
to do a great deal. We have asked context to fix $s, E$, and maybe even to derive a scale from $E$. It may be objected that context cannot do this.

The objection here is one from metasemantics. The semantics proposed for predicates of personal taste is not extraordinary. It contains some contextual parameters, but so do many natural-language constructions or classes of expressions. The semantics need not say how these parameters get their values fixed. That is the job of what we may, echoing Kaplan (1989a), call metasemantics. One of the jobs for metasemantics is to explain what it is that fixes the values of contextual parameters in contexts.

Metasemantics, especially the metasemantics of contextual parameters, is a notoriously messy subject, about which we understand relatively little. This is no failure of any given semantic analysis. For instance, though it falls on the simple side of metasemantics, it is already a very messy issue just how demonstrated objects are identified. However messy this may be, it is no reason to reject the semantics which says a demonstrative picks out a demonstrated object. Difficulties in the metasemantics here do not make us doubt the semantics itself. Even so, one might worry that some analyses make setting contextual parameters strange, unreasonable, theoretically unworkable, or even impossible. One might worry that some semantic analyses just require unacceptable metasemantics. Skepticism along these lines about the kind of parameter setting which my own proposal requires might provide motivation for adopting a view like Lasersohn's. If a parameter could not be set by context, relativism offers a way out, by putting it in the semantic values of sentences, where it does not have to be set once and for all. If we see metasemantic problems, we can avoid them by moving towards relativism. ${ }^{15}$

A full answer to this form of skepticism would be a detailed metasemantic story of how

\footnotetext{
${ }^{15}$ Lasersohn has told me that this is not in fact his motivation; rather, he sees the issue of disagreement as the main motivation for relativism. Metasemantic concerns are explicit in Richard (2004), which I shall discuss below. More generally, this sort of skepticism seems to me to have been an important, if too rarely made explicit, aspect of the philosophical debate.
} 
the contextual parameters my analysis requires are set. I cannot offer one. (Indeed, I think that complete metasemantic stories are at best exceptionally rare, and may never have been written down at all.) Instead, I shall argue that the case of predicates of personal taste on my proposal is not really any worse than that of other predicates derived from gradable adjectives. I shall then turn to an objection from Richard (2004), which in effect say that even that is unacceptable.

The analysis of gradable adjectives I borrowed from Kennedy (2007) posits a contextually determined function $s$ which takes as input the meaning of an adjective-understood as a function from individuals to degree values on an appropriate scale - and returns the standard for it in context. As the only input is the adjective meaning, determining this function makes heavy demands on context, much as my proposal does for adjectives of personal taste.

It is a common idea that a much more specific, and presumably simpler, contribution from context is required. According to this idea, context is supposed to hand us a comparison class, a contextually salient class of individuals to which the adjective might be applied, and which we are comparing. The comparison class may be made explicit by a for-phrase (cf. Klein, 1980), but if it is not made explicit, it must be provided by context. The standard is then computed from the comparison class, by applying a norm to it. For instance, we might take the standard for tall in a given context to be the average of the heights of the people in the comparison class. This makes the contribution of context much more limited. It basically needs to collect together some salient objects. From there, a fixed procedure tells us how to determine the value of the needed parameter.

Kennedy argues this picture is wrong. His argument is primarily semantic - not metasemantic. He argues that there is no semantic role for the comparison class to play. Among the many things context may make salient is a class of individuals being compared, but there is no parameter in the meaning of a gradable adjective which is set by such a class, and thus it plays no special role in fixing the interpretation of a gradable adjective in context. We 
might make use of the class in working out a contextually given $s$, but not by the kind of procedure just described.

Kennedy offers several arguments for this conclusion. One is somewhat technical. He notes that for-phrases do not function the way expressions that fix arguments should. Rather, they seem to trigger the presupposition that objects fall within the class fixed by the for-NP. Semantically, this cannot function to set the value of an argument. ${ }^{16}$ (Rather, according to Kennedy, the domain of the measure function is restricted by a for-phrase.)

Another of Kennedy's arguments is less technical. The analysis that fixes the standard via a norm of being average applied to a comparison class (expressed by a for-phrase) predicts that the following should be contradictory:

(19) Nadia's height is greater than the average height for a gymnast, but she is still not tall for a gymnast.

It is easy to find contexts where this is not contradictory. We can also find contexts where it is not contradictory if we change the norm, e.g. to the mode or median height, and likewise for any other plausible norm given the meaning of tall. Hence, no fixed norm applied to a comparison class will be able to uniformly get us the right truth conditions. ${ }^{17}$

With Kennedy, we should conclude that the standard is not uniformly computed from a comparison class, and that a comparison class is not itself a contextual parameter in a

${ }^{16}$ Kennedy observes that each of the following requires Kyle's car to be a Honda:

(i) a. Kyle's car is expensive for a Honda.

b. Kyle's car is not expensive for a Honda.

c. Is Kyle's car expensive for a Honda?

Furthermore, we see infelicity in:

(ii) a. ?? Kyle's BMW is expensive for a Honda.

b. ?? Kyle's BMW is not expensive for a Honda.

These are standard reasons to see Kyle's car is a Honda as presupposed.

${ }^{17}$ Kennedy (2007) and Fara (2000) also discuss ways that the norm plus comparison class analysis does not adequately address problems related to vagueness and the Sorites paradox. Kennedy credits the observation in (19) to Bogusławski (1975). 
gradable predicate. Rather, we must ask context to work out the value of $s$, and a comparison class might help do that.

The comparison class is not the only thing that might help. Kennedy argues at length that in some cases, the scale will have an important effect. Adjectives like dry and closed, which have a maximum value for their scale (completely dry, completely closed), at least usually require something to reach the maximum. To be dry is (usually) to be completely dry; to be closed is (usually) to be completely closed. Kennedy also suggests a general principle for computing contextual values: a principle of 'interpretive economy', which tells us to make as much use of the meanings of expressions as possible to compute what is expressed in context. This helps to explain why, when there is a maximum value provided by the meaning of an adjective, we use it to fix the standard.

What then fixes $s$ ? I have given no general theory, nor has Kennedy. But Kennedy has identified some important factors which are used to compute its value in context: salient properties of the context, such as salient comparison classes, the denotations of the expressions involved, and general rules like the interpretive economy principle. We can add to this list. For instance, intentions of speakers, their interests, and the structure of the discourse in which the utterance appears can be relevant to fixing a standard in context.

According to this view, a contextual parameter like $s$ is set by a computation based on a wide range of inputs from the context. Let us call this an indirect metasemantics. A contextual parameter with an indirect metasemantics must be set by the various pieces of information context provides, but context does not simply hand us a value for such a parameter, nor does it hand us a uniform rule for computing the value from a specific piece of contextual information. Rather, a range of contextual information and computational rules must be taken into account and weighed in working out the value from context.

In my contextualist response to relativism about adjectives of personal taste, I relied on contextual parameters which seem to require an indirect metasemantics. I then asked if that 
constituted an objection, on behalf of the relativist. My response so far has been that such indirect metasemantics is normal; at least, it seems to be required every bit as much for the contextual parameters in other gradable adjectives. Hence, I claim, I have made no demands on context beyond those we have good reason to think uncontroversial context dependence makes.

\section{Expanding Relativism?}

Generally, my defense against relativism for predicates of personal taste has been to argue that a contextualism no more problematic than that for gradable adjectives avoids relativism. I offered a contextualist account of predicates built from adjectives of personal taste, and argued that the kinds of contextual parameters needed are not metasemantically different from those required by other gradable adjectives. They require indirect metasemantics, but so do parameters in other gradable adjectives. I think the right response on the part of the relativist at this point is simply to say we should be relativists about gradable adjectives generally, not just adjectives of personal taste. I take it the motivation is that indirect metasemantics is unacceptable, and it should be replaced by relativism.

This is the conclusion reached by Richard (2004). To see where this sort of response might lead, let us consider Richard's arguments in detail. Like Lasersohn, Richard argues on the basis of intuitions about disagreement. He presents us with the following case, which focuses our attention on the gradable adjective rich.

Suppose two speakers, Didi and Naomi, have very different ideas about what counts as rich. Naomi does not think a million dollars counts as all that much, while Didi does. Mary has just won a million dollars in the lottery, and Didi says Mary is rich, while Naomi insists, Mary is not rich. As Richard describes the case, there are two different conversations, but the relevant comparison class is stipulated to be the same: the class of New Yorkers. It is 
further stipulated that nothing about the conversations relevant to richness differ. We then report:

(20) They disagree: one thinks Mary is rich, the other does not.

This appears to correctly report a disagreement between the two. But, Richard asks, how can that be, if contextualism about rich has its extension vary with the views of the speakers? If the extension of rich changes with the views of the speakers, then Didi's and Naomi's very different views of how much it takes to be rich should make them not really disagreeing at all.

To avoid this conclusion, and preserve the disagreement reported in (20), Richard proposes to relativize semantic values to agents, much as Lasersohn does. According to Richard, the very same proposition is involved in both Didi's and Naomi's utterances. That proposition is expressed by Didi and denied by Naomi, but it is furthermore true for Didi and not true for Naomi.

Richard makes admirably clear the metasemantic nature of his basic point. He grants that some features of context go into fixing the semantic value of a gradable adjective like rich or tall (he puts this in terms of comparison classes). But still, he maintains, once context has done its work, there is still a need to relativize to an agent. "[E]ven after we fix the reference class for it $[$ tall], we can adjust the point on the scale of height at which the cut off for being tall lies" (Richard, 2004, p. 229). Fixing the cut-off point is a matter of what Richard glosses as negotiation and accommodation. In particular, we can sometimes accommodate a speaker's views about what counts as tall or rich in the process of setting a standard. Other times, we wind up negotiating what the standard is to be, if different speakers have different ideas about what counts as tall or rich. It is these factors of accommodation and negotiation that Richard sees as marking the step from a contextual contribution to semantic value relativism. Where we see accommodation and negotiation, we see the views of particular speakers being expressed, debated, and accepted. To Richard, that must be a matter of 
assessing propositions, so we must see it as a matter of the coordinates of semantic values, not of fixing contextual parameters.

According to Richard, genuine contextual inputs are not subject to this sort of accommodation and negotiation. For instance, the comparison class (the "reference class") is not, as Richard sees it. Rather, he assumes that this class if fixed by the speaker's intentions, and is not subject to further negotiation. It is thus by his lights a genuine contextual factor. In contrast, the standards of what is to count as tall or rich are open to just such negotiation and accommodation. Thus, Richard holds, they cannot be accounted for by contributions of context, and so we are forced to relativism.

There are two issues raised by Richard, and I shall discuss them separately. One is how far relativism goes, the other is what the correct view of the metasemantics of context dependence is. Above I described the metasemantics that goes with contextualism for gradable adjectives according to Kennedy, and adjectives of personal taste according to me, as 'indirect'. It is fairly clear that Richard is assuming a very different picture of the metasemantics of contextual parameters. I shall discuss this more in the next section. But for the remainder of this section, let us consider how far relativism will go, if we follow Richard's lead.

I shall argue that if we agree that any time we have accommodation and negotiation we have a case for relativism, we will wind up with a great deal of relativism indeed. We will wind up with just the sort of open-ended indices which the index theory proposed, and were rejected by Cresswell.

Accommodation and negotiation are wide-spread. Take, for instance, quantifier domain restriction. Suppose I say:

(21) Every philosopher is smart.

Take this to have a restricted reading - something near to 'every philosopher around here (at a conference, among those I interact with, ... ) is smart'. We see accommodation in cases like this all the time. You work out what I might have in mind when I say every philosopher, 
and accommodate it into the conversational record. But we also see negotiation. If we encounter a person who is not smart, but only tangentially associated with the conditions restricting the domain of philosophers, we can have a discussion of whether he falls within the domain determined by the context. It is important to note here that I do not simply get to decide: I cannot just say he does not count and still be assessing the claim I originally made. My intentions probably count a great deal, and may be the main determining factor in some case of domain restriction, but that does not mean we do not negotiate how the domain is derived from them. ${ }^{18}$

Suppose we assume, with Lasersohn and with Richard, that there is something like a judge parameter in semantic values. Does that allow us to compute the accommodatable and negotiable aspects of quantifier domain restriction? Not without cheating. From the judge, we may get some additional intentions (over and above the speaker's?), but we will need to know which intentions are directed at fixing the quantifier domain, and how. We will also need, from the judge or the world, what satisfies the relevant intentions. Furthermore, in many cases, this will all be more factors, on par with the others we have considered. We will still need other speakers' intentions, and facts about the discourse and environment, to work out the quantifier domain. Pretty much all of this will be subject to accommodation and negotiation. If we wish to avoid any contextual parameters subject to accommodation and negotiation, we have a problem with quantifier domains, even if we assume semantic value relativism to judges.

The difference here with adjectives like tasty and fun is striking. There, as Lasersohn set things up, it is the meanings of these words that fixes what we do with the judge. Fun means fun for the judge, and the predicate meaning itself takes the judge and world as input and works out extensions. Once we have the judge, we have no further room for accommodation

\footnotetext{
${ }^{18} \mathrm{~A}$ more extreme position, advocated by Gauker (1997), insists that there is no role for speakers' intentions here. I do not need this stronger claim, but only that they may be one of many factor relevant to some cases, as an indirect metasemantics should have it.
} 
or negotiation. But for cases like quantifier domains, we still have lots of room for accommodation and negotiation. It might be, perhaps, that in some metaphysical sense fixing a world (and time), and with the relativists, fixing a judge, suffices to fix everything, including quantifier domains. But this seems to do little more than assure us that it is metaphysically fixed how the metasemantic processes that determine quantifier domains will proceed, including processes of accommodation and negotiation. This is of no help to the semantics of quantifiers, which requires a quantifier domain itself, nor to the metasemantics, which relies on the very processes which allow accommodation and negotiation. If the relativist requires additional coordinates in indices whenever we encounter accommodation and negotiation, he will have to add a quantifier domain coordinate to indices, over and above the judge coordinate.

Once we take a step down this road, we will wind up with all sorts of coordinates. Even in the case of the standard for a gradable adjective, it seems we will need not only a judge coordinate, but a separate coordinate for the function $s$ itself. As we have seen, to get from a judge to the value of $s$, we will have to take into account many extra factors, such as various speakers' intentions, facts about salient objects (which fix comparison classes), and the lexical properties of the relevant adjective (the scale properties), and many other features of context. We are back in the realm of accommodation and negotiation. ${ }^{19}$ More generally, as I shall argue in the next section, we are back in the realm of indirect metasemantics.

We began with the idea that we might want to add a judge coordinate to indices that make up semantic values. But, I have argued, the Richard-type reasons to do so will lead us way past a judge coordinate. We now have coordinates for a judge, quantifier domain, and standard function. And of course, things do not stop there either. We will have to add multiple quantifier domain coordinates, at least. But we will also have to add many other

\footnotetext{
${ }^{19}$ Aspects of accommodation for the standard for a gradable predicate are discussed by Barker (2002) and Kyburg and Morreau (2000).
} 
sorts of coordinates as well. For instance, to account for modals, we will have to add at least additional coordinates for a set of worlds and an accessibility relation (or a coordinate for the 'modal base' of Kratzer, 1981). These show similar metasemantic features to the parameters in gradable adjectives, and so if we are to be relativist about the latter, we will have to be about the former too. Likewise, possessive constructions might require additional coordinates, as we may find ourselves accommodating or negotiating just what counts as a possession relation. Some coordinate to account for presupposition will also have to be added, as presuppositions are the prime examples of accommodation.

This is something of an embarrassment of relativism. We have gone way beyond 'true for you and true for me'. We now have 'true for you, a domain, a standard function, a modal base, a possession relation, and so on'. We have, by now, returned to the Cresswell objection. Just as Cresswell observed, once we start adding coordinates to indices, we will not be able to stop. Some of Cresswell's original examples might no longer be necessary. (We might avoid a climate parameter for What a cold winter we've had by a careful analysis of cold.) But we have seen that his basic point that we can keep finding new coordinates if we start allowing them holds all the better. If we add coordinates to indices any time we have the kind of metasemantics which will lead to accommodation and negotiation, we will wind up with just the kind of open-ended indices Cresswell pointed out.

To stress this point, let me mention yet one more example, which shows how far we will have to go in adding coordinates, and also has some metasemantic implications. We will need a separate coordinate for alternative set or contrast class (cf. Rooth, 1985, 1992). Here's an example I've talked about before (Glanzberg, 2002, examples 17 and 18). It involves a sentence containing a stressed element (more properly, a focused element ${ }^{20}$ ), and two contexts given by little discourses:

\footnotetext{
${ }^{20}$ A survey of focus may be found in Rooth (1996). I discuss some of its philosophical implications in my $(2005)$.
} 
Only the HOUSE was visible from the trees.

The detective: I sat in the trees all night. No one came or went. No one let the dog out. No cars passed. There were no toys on the lawn. Maybe it looked different from the other side, but only the HOUSE was visible from the trees.

The landscape designer: In front of the house was a small garden, leading to a substantial lawn, which was surrounded by trees. An isolated space was formed. Only the HOUSE was visible from the trees.

The detective's claim, as we told the story, appears true; while assuming the garden to be in the line of sight from the trees, the landscape designer's claim is false. What is the relevant difference? Each claim means only the house, as opposed to other contextually given alternatives. For the detective's context, those are people and cars, etc. For the landscape designer's, they are things like the house itself, the garden, the lawn, the porch of the house, etc. It also appears that something like 'spaces' are among the alternatives.

I have argued elsewhere (2002) that we can only work out what the contextually given set of alternatives is by paying attention to the large-scale structure of the discourse in which a sentence appears. Why, for instance, do the shingles on the roof and the water faucet carefully concealed in the garden not seem to count? But for the moment, we may just note that working out an alternative set in cases like this is at least as complicated, or maybe much more so, than computing the contextual parameters for a gradable adjective. It is highly indirect: perhaps at the extreme of how indirect the metasemantics of contextual parameters can be. It will certainly run us into all the problems of accommodation and negotiation. We will need to add an alternative set coordinate to our indices, if we take this to be a reason for relativism. We thus see one more way in which indices will expand to include more, and more recondite, coordinates, if we go down the relativist road.

Let us take stock. We began by considering arguments in favor of relativism about predicates of personal taste. For these, the agent plays a special role, so perhaps relativism 
for them seemed banal. At least, fun for you and fun for me don't sound that strange. However, I argued that a contextualist approach to these sorts of expressions does just as well, and keeps them on par with other gradable adjectives. This seems to me to be good reason to reject relativism for them. But I went on to consider the response that to the contrary, it shows we should be relativists in the face of ordinary gradable adjectives too. I've argued that if so, we re-encounter a form of the Cresswell objection. Our semantic value relativism will require not just adding a judge coordinate, but many other coordinates as well. As Cresswell suggested, it is not clear where such a list will stop.

This is a worry for two reasons. First, our credulity for relativism should be further strained, especially when we consider the sorts of things that will have to be added to indices. 'True for a quantifier domain' and 'true for a modal base' and 'true for an alternative set' just sound crazy. But more importantly, as I noted when first introducing the Cresswell objection, the components that go into building semantic values are part of the semantics of a language. As I argued above, having the semantic value of any sentence be built from such a long, or worse, open-ended indices raises serious problems about semantic competence. This shows that such indices are not appropriate for the job of giving the semantic values of sentences. As that is exactly what such indices are for, we may conclude that any form of semantic value relativism that is committed to them is untenable.

Contextualism, I have argued, is the better option when it comes to predicates of personal taste. If we take predicates of personal taste to be among the better cases for semantic value relativism, we can with all due caution generalize to the conclusion that well-thought-out contextualism undercuts the case for relativism. The sort of contextualism I have proposed requires an indirect metasemantics. Rejecting indirect metasemantics might thus provide a reason for relativism. At least, it seems that the case for relativism only gets off the ground if we reject indirect metasemantics. In the instance of Richard's rejection of contextual parameters subject to accommodation and negotiation, I argued that this leads to open- 
ended indices, and so is untenable. Again, we may generalize. After exploring the distinction between direct and indirect metasemantics further in the next section, I shall show that accommodation and negotiation are the typical marks of indirect metasemantics. Thus, we only get to semantic value relativism by rejecting indirect metasemantics; but doing so leads to a rampant form of semantic value relativism, that is committed to an untenable index theory. This is good reason to reject relativism.

We may also extract a positive moral for contextualism from the argument based on the Cresswell objection. The argument in effect shows that contextual parameters requiring indirect metasemantics are widespread in natural language. Thus, the metasemantic demands of the contextualism I have proposed are not unusual. This is a further reason to accept contextualism, as well as a reason to reject relativism.

\section{What Fixes Contextual Parameters?}

The only path towards relativism that takes us anywhere takes us too far. It makes too much of what we would normally recognize as context dependence become a matter of coordinates in semantic values. It thus runs afoul of the Cresswell objection, not to mention just straining credulity.

But we do face a trade-off when we come to metasemantics. To avoid rampant relativism, I have argued for contextual parameters which require highly indirect metasemantics. What fixes their values will be complicated combinations of such factors as what is salient in the environment, speakers' intentions, hearers' intentions, coordinating intentions, linguistic meaning, general principles governing context, discourse structure, etc. From these resources, values will have to be computed. The alternative set example shows just how complicated the information involved can be, and indeed, in the alternative set cases, it is information

which might not be transparent to speakers at the time of utterance. As Richard rightly 
reminds us, such computations will often allow for accommodation and negotiation.

The indirect picture of metasemantics is based on the model of the metasemantics of contextual parameters like standards, or harder cases like alternative sets. The contrasting picture, which we may call that of direct metasemantics, is based on the model of the metasemantics of demonstratives or deictic pronouns. For instance, someone says:

(23) That is my favorite.

Though I mentioned when introducing metasemantics that the way the referent of that is fixed is not entirely straightforward, it is quite simple, compared to the kinds of parameters we have been examining. There are roughly two options for how the referent of that is fixed: either it is a demonstration - a publicly observable feature of an utterance event like a pointing gesture - which fixes the referent, or it is a referential intention which does so. The discussion of which of these takes priority is lengthy, but for the moment, either will do for the point at issue here. ${ }^{21}$ If intentions are involved, they are referential intentions, which the speaker more or less explicitly has. If it is gestures or other public aspects of the utterance, they are gestures that the speaker can publicly make. The speaker, or the environment, in effect, directly sets the value of the contextual parameter, by directly forming an intention or making a gesture.

The picture I roughly sketched of how the parameters in gradable adjectives get set is enough to show they are set very differently from this. Many contributing factors are involved, sometimes competing factors, from which a value is worked out. No single publicly observable feature of the context directly assigns the value, in the way a pointing gesture might fix reference. Nor do speakers form anything like a referential intention to set the value. For instance, speakers do not have anything like a referential intention which fixes the value of the standard function $s$.

\footnotetext{
${ }^{21}$ The question of what fixes the referent of a demonstrative was raised by Kaplan (1989b). He notoriously changed his mind on the issue in Kaplan (1989a). For more recent references and discussion, see Siegel (2002).
} 
Those with intentionalist intuitions might hold that really speakers' intentions trump all the other factors. But in cases like a standard function, this is not so. First of all, it is not clear how a speaker's intentions could directly set $s$. Unlike a demonstrative or deictic pronoun, it is not clear that many speakers could form any kind of conscious intention related to it at all. Perhaps they have tacit ones, but just what they are like is not at all clear. Distinguishing such intentions from speakers' beliefs about what is, for instance, tall or rich, would be very difficult.

Insofar as speakers might have intentions or beliefs about what 'makes something count', they do not automatically fix standards. They may, in some contexts, but they need not. There are several ways they may fail to do so.

As Kennedy (2007) notes, the meaning of an adjective may overrule any intentions or beliefs on the part of the speaker. In most contexts, dry means totally dry, in spite of whatever idiosyncratic beliefs about what counts as dry a speaker might have.

In many contexts, the salient individuals to which we might compare something (the comparison class) play a significant role in setting the standard. If I am a six foot six inch basketball player, talking to my teammates about who is tall enough to be effective, I cannot whimsically intend to set the standard at a value more appropriate for jockeys. My claim that Jones is tall will not in this setting mean that Jones is tall for a jockey, regardless of my whim. It will certainly not if I happen to just have very idiosyncratic beliefs about who is tall.

In some cases, it is not what is salient in the environment, but shared presuppositions, which seem to matter. At a conference on international development, the standard for richness (be it for a nation or a person) will require something like, say, having a billion disposable dollars. My insisting the standard is really having one thousand dollars won't change the content of what I say. Nor will my having idiosyncratic beliefs about money, which could lead me to believe that having one thousand dollars is really being rich for that 
context. The latter is, presumably, an odd set of beliefs about what values on the scale different people or countries have, not a parameter-setting intention at all. ${ }^{22}$

The metasemantics of the parameters in gradable adjectives is indirect. It is not simply a matter of anything like referential intentions, or other factors acceptable according to the model of direct metasemantics. We have seen that many other contextual parameters will be metasemantically on par with those in gradable adjectives as well. It thus seems that language presents us with many instances of contextual parameters with indirect metasemantics. This indeed makes us wonder how we ever succeed in determining propositional content. But regardless, it does appear to be the way metasemantics works in many cases.

As Richard in effect notes, direct metasemantics does not allow for accommodation or negotiation. It assumes there is something like a fixed public feature of context, like a pointing gesture, or a single directing intention, like a referential intention, which fixes the value of a parameter. These are not open to negotiation, nor is there any interesting accommodation of them to be done. In contrast, indirect metasemantics will very often allow accommodation and negotiation. When there are many factors which must be weighed, none of which is a direct parameter-setter like a referential intention, we expect opportunities for accommodation and negotiation in identifying the relevant features of context, and computing the value of a parameter from them.

I believe that the acceptability of indirect metasemantics is a key point of contention that lies behind the debates about semantic value relativism I have been discussing. I defended contextualism over relativism for predicates of personal taste, by providing them with a semantics which requires an indirect metasemantics. Richard, on the other hand, in effect insists on only direct metasemantics, and where it cannot be found, he proposes relativism.

\footnotetext{
${ }^{22}$ One point that is made vivid by parameters with indirect metasemantics is that speakers can wind up in significant error or ignorance about what they have semantically expressed. For the record, I think this is a result we should accept, though when it comes to personal taste, it raises a number of issues I do not have space to pursue here.
} 
Hence, he finds all gradable adjectives to implicate relativism. The motivation for relativism seems to be finding indirect metasemantics too mysterious, and finding relativism better.

I have not settled the question of whether we can make sense of indirect metasemantics, and hence, whether my defense of contextualism over relativism will stand. I have argued that contextual parameters with indirect metasemantics appear to be wide-spread in natural language, and used this to construct a Cresswell-style argument against relativism. If they are as wide-spread as I suspect, then rather than become relativists, we should just try to understand them better.

\section{References}

Barker, C., 2002. The dynamics of vagueness. Linguistics and Philosophy 25:1-36.

Bartsch, R. and T. Vennemann, 1973. Semantic Structures: A Study in the Relation between Semantics and Syntax. Frankfurt: Athenäum, 2nd edn.

Bierwisch, M., 1989. The semantics of gradation. In M. Bierwisch and E. Lang (eds.), Dimensional Adjectives, pp. 71-261. Berlin: Springer-Verlag.

Bogusławski, A., 1975. Measures are measures: In defense of the diversity of comparatives and positives. Linguistische Berichte 36:1-9.

Cappelen, H. and E. Lepore, 2005. Insensitive Semantics. Oxford: Blackwell.

Cresswell, M. J., 1973. Logics and Languages. London: Methuen.

— 1977. The semantics of degree. In B. Partee (ed.), Montague Grammar, pp. 261-292. New York: Academic Press.

Egan, A., 2007. Epistemic modals, relativism, and assertion. Philosophical Studies 133:1-22.

Egan, A., J. Hawthorne, and B. Weatherson, 2005. Epistemic modals in context. In G. Preyer and G. Peter (eds.), Contextualism in Philosophy, pp. 131-168. Oxford: Oxford University Press.

Enç, M., 1984. Anchoring conditions for tense. Linguistic Inquiry 18:633-657.

- 1986. Towards a referential analysis of temporal expressions. Linguistics and Philosophy 9:405-426. 
Evans, G., 1985. Does tense logic rest upon a mistake? In Collected Papers, pp. 342-362. Oxford: Oxford University Press.

Fara, D. G., 2000. Shifting sands: An interest-relative theory of vagueness. Philosophical Topics 20:45-81. Originally published under the name 'Delia Graff'.

Fine, K., 1975. Vagueness, truth and logic. Synthese 30:265-300.

Fults, S., 2005. Comparison and compositionality. Proceedings of the West Coast Conference on Formal Linguistics 24:146-154.

Gauker, C., 1997. Domain of discourse. Mind 106:1-32.

Glanzberg, M., 2002. Context and discourse. Mind and Language 17:333-375.

- 2005. Focus: A case study on the semantics-pragmatics boundary. In Z. G. Szabó (ed.), Semantics versus Pragmatics, pp. 72-110. Oxford: Oxford University Press.

Heim, I., 1985. Notes on comparatives and related matters. Unpublished ms, University of Texas, Austin, available at http://semanticsarchive.net/Archive/zc0ZjY0M/.

Huang, C.-T. J., 1982. Logical Relations in Chinese and the Theory of Grammar. Ph.D. dissertation, MIT.

Kamp, H., 1975. Two theories about adjectives. In E. L. Keenan (ed.), Formal Semantics of Natural Language, pp. 123-155. Cambridge: Cambridge University Press.

Kaplan, D., 1989a. Afterthoughts. In J. Almog, J. Perry, and H. Wettstein (eds.), Themes from Kaplan, pp. 565-614. Oxford: Oxford University Press.

—, 1989b. Demonstratives. In J. Almog, J. Perry, and H. Wettstein (eds.), Themes From Kaplan, pp. 481-563. Oxford: Oxford University Press. First publication of a widely circulated manuscript dated 1977.

Kennedy, C., 1997. Projecting the Adjective. Ph.D. dissertation, University of California, Santa Cruz. Published by Garland, 1999.

— 2007 . Vagueness and grammar: The semantics of relative and absolute gradable adjectives. Linguistics and Philosophy 30:1-45.

King, J. C., 2003. Tense, modality, and semantic value. Philosophical Perspectives 17:195245.

Klein, E., 1980. A semantics for positive and comparative adjectives. Linguistics and Philosophy 4:1-45.

Kölbel, M., 2002. Truth Without Objectivity. London: Routledge. 
Kratzer, A., 1981. The notional category of modality. In H.-J. Eikmeyer and H. Rieser (eds.), Words, Worlds, and Contexts, pp. 38-74. Berlin: de Gruyter.

Kyburg, A. and M. Morreau, 2000. Fitting words: Vague language in context. Linguistics and Philosophy 23:577-597.

Landau, I., 2000. Elements of Control. Dordrecht: Kluwer.

Larson, R. K., 1988. Implicit arguments in situation semantics. Linguistics and Philosophy 11:169-201.

Lasersohn, P., 2005. Context dependence, disagreement, and predicates of personal taste. Linguistics and Philosophy 28:643-686.

, forthcoming. Relative truth, speaker commitment, and control of implicit arguments. Proceedings of the North East Linguistics Society 37.

Lasnik, H. and M. Saito, 1984. On the nature of proper government. Linguistic Inquiry 15:235-289.

Lewis, D., 1970. General semantics. Synthese 22:18-67. Reprinted in Lewis (1983).

- 1980. Index, context, and content. In S. Kanger and S. Öhman (eds.), Philosophy and Grammar, pp. 79-100. Dordrecht: Reidel. Reprinted in Lewis (1998).

—, 1983. Philosophical Papers, vol. 1. Oxford: Oxford University Press.

—, 1998. Papers in Philosophical Logic. Cambridge: Cambridge University Press.

MacFarlane, J., 2003. Future contingents and relative truth. Philosophical Quarterly 53:321336. 339.

McConnell-Ginet, S., 1973. Comparative Constructions in English: A Syntactic and Semantic Analysis. Ph.D. dissertation, University of Rochester.

Montague, R., 1968. Pragmatics. In R. Klibansky (ed.), Contemporary Philosophy: A Survey, pp. 102-122. Florence: La Nuova Italia Editrice. Reprinted in Montague (1974).

— , 1974. Formal Philosophy. New Haven: Yale University Press. Edited by R. Thomason.

Pinkal, M., 1995. Logic and Lexicon. Dordrecht: Kluwer.

Richard, M., 1981. Temporalism and eternalism. Philosophical Studies 39:1-13.

—, 1982. Tense, propositions, and meanings. Philosophical Studies 41:337-351. 
—, 2004. Contextualism and relativism. Philosophical Studies 119:215-242.

Rooth, M., 1985. Association with Focus. Ph.D. dissertation, University of Massachusetts at Amherst.

- 1992. A theory of focus interpretation. Natural Language Semantics 1:75-116.

— 1996. Focus. In S. Lappin (ed.), Handbook of Contemporary Semantic Theory, pp. 271-297. Oxford: Blackwell.

Siegel, S., 2002. The role of perception in demonstrative reference. Philosopher's Imprint $2: 1-21$.

Stanley, J., 2000. Context and logical form. Linguistics and Philosophy 23:391-434.

—, 2005. Knowledge and Practical Interest. Oxford: Oxford University Press.

von Stechow, A., 1984. Comparing semantic theories of comparison. Journal of Semantics $3: 1-77$.

Williams, E., 1995. Theta theory. In G. Webelhuth (ed.), Government and Binding Theory and the Minimalist Program, pp. 97-124. Oxford: Blackwell.

Wright, C., 1992. Truth and Objectivity. Cambridge: Harvard University Press. 